\title{
PENERAPAN SUMUR RESAPAN UNTUK PENGENDALIAN GENANGAN AIR HUJAN PADA AREA RUMAH TINGGAL
}

\author{
Ni Ketut Utami Nilawati ${ }^{1}$, I Gde Eka Dharsika ${ }^{2}$ \\ ${ }^{1}$ Program Studi Teknik Informatika, Fakultas Teknik, STIMIK STIKOM Indonesia, \\ Jl. Tukad Pakerisan Nomor 97 Denpasar, Bali. \\ Email: utaminilawati@gmail.com \\ ${ }^{2}$ Program Studi Teknik Informatika, Fakultas Teknik, STIMIK STIKOM Indonesia, \\ Jl. Tukad Pakerisan Nomor 97 Denpasar, Bali. \\ Email: e.dharsika@gmail.com
}

\begin{abstract}
Abstrak - Pembangunan yang terus menerus menyebabkan perubahan tata guna lahan dari ruang terbuka sebagai lahan resapan air berubah menjadi areal perumahan. Alih fungsi lahan resapan air menyebabkan air hujan yang jatuh pada lahan tersebut tidak masuk ke dalam tanah, tetapi melimpas di permukaan tanah. Ketika musim hujan sebagian besar air akan terbuang langsung ke laut, selain itu akan menimbulkan genangan air dan banjir. Sedangkan ketika musim kemarau, sumber air tanah banyak yang mengalami kekeringan. Secara alami, kekurangan air tanah dapat diatasi apabila sistem pengelolaan ditangani secara baik.

Rumusan masalah pada penelitian ini adalah bagaimana penerapan sumur resapan untuk pengendalian genangan air hujan pada area rumah tinggal.

Prinsip kerja dari sumur resapan adalah menyalurkan dan menampung air hujan ke dalam sebuah lubang atau sumur, dimana air hujan yang ada di permukaan tanah selanjutnya akan meresap secara perlahan ke dalam tanah. Di bawah tanah, air yang meresap ini akan merembes masuk ke dalam lapisan tanah yang disebut lapisan tidak jenuh, dimana lapisan ini masih bisa menyerap air. Dengan demikian, masuknya air hujan ke dalam tanah akan menambah air tanah. Penerapan sumur resapan pada area rumah tinggal diperlukan data perhitungan luas area yang tertutup bangunan dan kedap air. Jumlah area sumur resapan yang perlu dibuat adalah $4 \%$ dari area kedap air.
\end{abstract}

Kata kunci: sumur resapan; pengendalian; genangan air hujan.

\begin{abstract}
Continuous development causes changes in land use from open spaces as water catchment areas to become residential areas. The change in function of water catchment land causes rainwater that falls on the land not to enter the soil, but overflows on the surface of the soil. During the rainy season, most of the water will be discharged directly into the sea, otherwise it will cause puddles and flooding. Meanwhile, during the dry season, many groundwater sources experience drought. Naturally, groundwater shortages can be overcome if the management system is handled properly.

The formulation of the problem in this study is how to apply infiltration wells to control rainwater puddles in residential areas.

The working principle of an infiltration well is to distribute and collect rainwater into a hole or well, where the rainwater on the ground will then slowly seep into the ground. Below the ground, this seeping water will seep into the soil layer called the unsaturated layer, where this layer can still absorb water. Thus, the entry of rainwater into the ground will increase groundwater. The application of infiltration wells in residential areas requires calculation of the area covered by buildings and watertight. The number of infiltration well areas that need to be made is $4 \%$ of the watertight area.
\end{abstract}

Keywords: infiltration; controlling; rainwater puddle. 


\section{Pendahuluan}

Menurut (Duppa, 2017) Sumur resapan merupakan suatu upaya untuk meresapkan air hujan dalam rangka menambah cadangan air tanah. Hal ini mengingat persediaan air tanah sudah sangat menipis, ditambah lagi dengan masalah air lainnya seperti kelebihan air di saat musim hujan yang menimbulkan banjir dan musim kemarau sering mengalami kekurangan air, sehingga seluruh masyarakat sebaiknya menyadari dan menyelamatkan air. Sumur resapan berfungsi untuk mencegah penurunan tanah, mengurangi genangan, mengurangi meluasnya penyusupan/instrusi laut ke arah daratan dan menambah potensi air tanah.

Prinsip kerja dari sumur resapan adalah menyalurkan dan menampung air hujan ke dalam sebuah lubang atau sumur, dimana air hujan yang ada di permukaan tanah selanjutnya akan meresap secara perlahan ke dalam tanah. Di bawah tanah, air yang meresap ini akan merembes masuk ke dalam lapisan tanah yang disebut lapisan tidak jenuh, dimana lapisan ini masih bisa menyerap air. Dengan demikian, masuknya air hujan ke dalam tanah akan menambah air tanah.

\section{Metodologi}

Perhitungan jumlah sumur resapan air hujan pada suatu area rumah tinggal dimulai dengan mempersiapkan data-data yang akan digunakan untuk menghitung. Data tersebut adalah jumlah lahan dan jumlah area yang tertutupi bangunan konkrit. Kedua data tadi akan sangat berguna dan tentunya harus didukung oleh adanya layout dengan skala yang menjelaskan tentang luas tersebut.

Untuk area penempatan sumur resapan adalah di dekat bangunan yang terdapat pipa talang limpasan air hujan. Diketahui luas area adalah $500 \mathrm{~m}^{2}$ dan luas area yang tertutup bangunan dan kedap air adalah $200 \mathrm{~m}^{2}$. Maka jumlah area sumur resapan yang perlu dibuat adalah $4 \%$ dari area kedap air, yaitu $4 \% \times 200=8 \mathrm{~m}^{2}$.

Untuk jumlah sumur resapan dalam unit adalah total luas area sumur resapan yang harus dibangun, dibagi dengan volume sumur resapan yang akan dibuat. Desain sumur resapan yang dibuat memiliki volume $0,78 \mathrm{~m}^{3}$.
Total sumur resapan dalam unit adalah : $8 \mathrm{~m}^{2}$ : $0,78 \mathrm{~m}^{3}=10$ buah sumur resapan.

\section{Hasil dan pembahasan}

Sumur resapan adalah sarana yang berbentuk seperti sumur dengan kedalaman tertentu yang berfungsi untuk menampung air hujan dan meresapkannya ke dalam tanah. Sumur resapan dapat mengurangi aliran air permukaan sehingga dapat mencegah banjir.

Sumur resapan pada umumnya berbentuk silinder dengan menggunakan buis beton sebagai dindingnya.

Sumur resapan yang direncanakan dengan diameter $1 \mathrm{~m}$ sedalam $1 \mathrm{~m}$. Perhitungan estimasi pekerjaan adalah sebagai berikut :

- Luas penampang sumur resapan $=1 / 4 \times \pi x$ $\mathrm{d}^{2}=1 / 4 \times 3,14 \times 1 \mathrm{~m}^{2}=0,78 \mathrm{~m}^{2}$

- Galian = Luas penampang sumur resapan $x$ tinggi sumur resapan

$$
=0,78 \mathrm{~m}^{2} \times 1 \mathrm{~m}=0,78 \mathrm{~m}^{3}
$$

- Buis beton diameter $1 \mathrm{~m}$

- Lapisan batu pecah $30 \mathrm{~cm}=$ luas penampang sumur resapan $x$ tinggi lapisan batu pecah

$=0,78 \mathrm{~m}^{2} \times 0,3 \mathrm{~m}=0,23 \mathrm{~m}^{3}$

- Lapisan puing bata dan genteng $30 \mathrm{~cm}=$ luas penampang sumur resapan $x$ tinggi lapisan pecahan bata dan genteng $=0,78 \mathrm{~m}^{2} \times 0,3 \mathrm{~m}=0,23 \mathrm{~m}^{3}$

- Lapisan ijuk $20 \mathrm{~cm}$ = luas penampang sumur resapan $\mathrm{x}$ tinggi lapisan ijuk $=0,78 \mathrm{~m}^{2} \times 0,2 \mathrm{~m}=0,16 \mathrm{~m}^{3}$

- Lapisan batu koral $20 \mathrm{~cm}=$ luas penampang sumur resapan $x$ tinggi batu koral $=0,78 \mathrm{~m}^{2} \times 0,2 \mathrm{~m}=0,16 \mathrm{~m}^{3}$

Gambar 1. Estimasi Biaya 1 Unit Sumur Resapan

\begin{tabular}{|c|c|c|c|c|c|}
\hline No & Uraian & Volume & Satuan & $\begin{array}{c}\text { Harga Satuan } \\
\text { (Rp) }\end{array}$ & $\begin{array}{c}\text { Jumlah } \\
\text { Harga (Rp) }\end{array}$ \\
\hline 1 & Galian Tanah & 0,78 & $\mathrm{~m}^{3}$ & 85.000 & 66.300 \\
\hline 2 & Buis Beton D $100 \mathrm{~cm}$ & 1,00 & $\mathrm{~m}^{1}$ & 568.000 & 568.000 \\
\hline 3 & $\begin{array}{l}\text { Lapisan Batu Pecah } \\
30 \mathrm{~cm}\end{array}$ & 0,23 & $\mathrm{~m}^{3}$ & 250.000 & 57.500 \\
\hline 4 & $\begin{array}{l}\text { Lapisan Puing Bata } \\
\text { dan Genteng } 30 \mathrm{~cm}\end{array}$ & 0,23 & $\mathrm{~m}^{3}$ & 100.000 & 23.000 \\
\hline 5 & Lapisan Ijuk $20 \mathrm{~cm}$ & 0,16 & $\mathrm{~m}^{3}$ & 230.000 & 36.800 \\
\hline 6 & $\begin{array}{l}\text { Lapisan Batu Koral } \\
20 \mathrm{~cm}\end{array}$ & 0,16 & $\mathrm{~m}^{3}$ & 500.000 & 80.000 \\
\hline \multicolumn{5}{|r|}{ Total } & 831.600 \\
\hline
\end{tabular}

Sumber : (Nilawati, 2020)

Penempatan sumur resapan adalah di dekat bangunan yang terdapat pipa talang limpasan air hujan dan pada area lainnya yang menimbulkan genangan air hujan. Sebagai 
salah satu sumber daya alam, air hujan merupakan suatu benda alam yang sangat penting untuk dilestarikan keberadaannya. Bila air hujan dibiarkan menggenang di lingkungan tanpa adanya sarana untuk mengalirkan dan meresapkannya ke dalam tanah misalnya melalui sumur resapan air hujan, maka akan sangat mengganggu kesehatan lingkungan.

Desain sumur resapan yang dibuat memiliki volume $0,78 \mathrm{~m}^{3}$. Sehingga dihitung total sumur resapan dalam unit adalah $8 \mathrm{~m}^{2}: 0,78 \mathrm{~m}^{3}=$ 10,25 buah sumur resapan, yang dibulatkan menjadi 10 buah sumur resapan. Untuk gambar rencana penempatan sumur resapan ditampilkan seperti pada gambar di bawah ini :

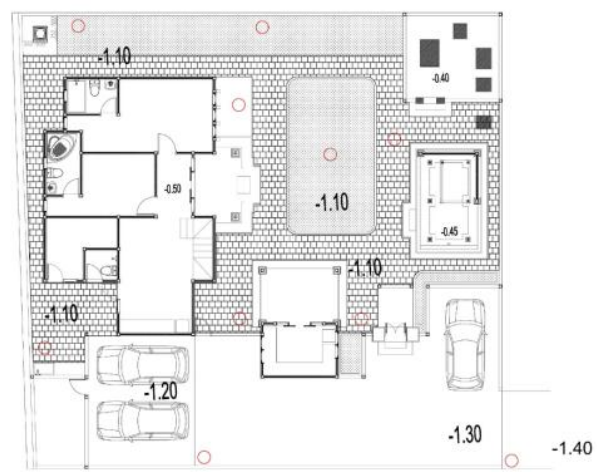

Gambar 2. Denah Penempatan Sumur Resapan

Sumber : (Nilawati, 2020)

Penerapan sumur resapan pada area rumah tinggal melalui langkah-langkah sebagai berikut:

1. Menentukan lokasi yang tepat untuk dijadikan sumur resapan

a. Lokasi sumur resapan pada lahan yang datar

b. Struktur tanah mempunyai sifat menyerap air

c. Jauh dari septic tank, jarak minimal $10 \mathrm{~m}$ dari septic tank

d. Kedalaman galian sampai pada tanah berpasir

2. Memilih jenis material pengisi sumur resapan. Jenis-jenis materialnya adalah :
a. Batu pecah
b. Puing bata dan genteng
c. ljuk

d. Batu koral bulat

3. Proses pembuatan sumur resapan :

a. Menyediakan tukang gali dan alat gali tanah

b. Mengukur luas area yang akan digali yaitu $1 \mathrm{~m} \times 1 \mathrm{~m}$

c. Pekerjaan galian sumur resapan mencapai kedalaman $1 \mathrm{~m}$

d. Pemasangan 2 buah buis beton diameter $1 \mathrm{~m}$ dan tinggi $0,5 \mathrm{~m}$

e. Pekerjaan mengisi bagian dalam sumur resapan, dimulai dengan :

- Batu pecah setinggi $30 \mathrm{~cm}$

- Puing bata dan genteng setinggi 30 $\mathrm{cm}$

- ljuk setinggi $20 \mathrm{~cm}$

- Batu koral setinggi $20 \mathrm{~cm}$

Sumur resapan air hujan pada area rumah tinggal dibuat untuk mengatasi genangan air hujan yang jatuh di sekitar lingkungan pekarangan rumah atau melalui atap rumah. Berikut adalah gambar pekerjaan sumur resapan :

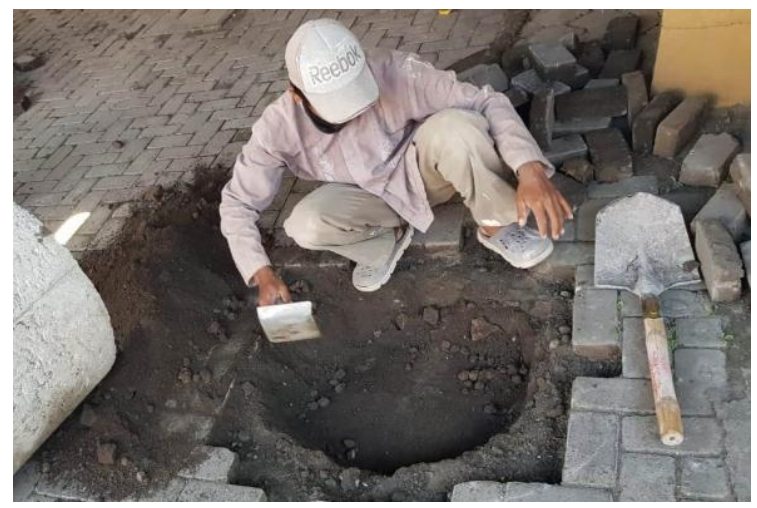

Gambar 3. Pekerjaan Galian Sumber : Nilawati, 2020)

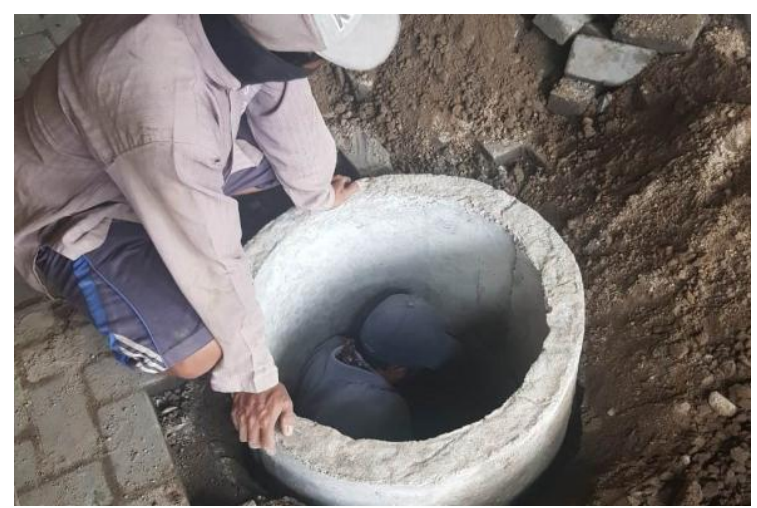

Gambar 4. Pemasangan Buis Beton Sumber : (Nilawati, 2020) 


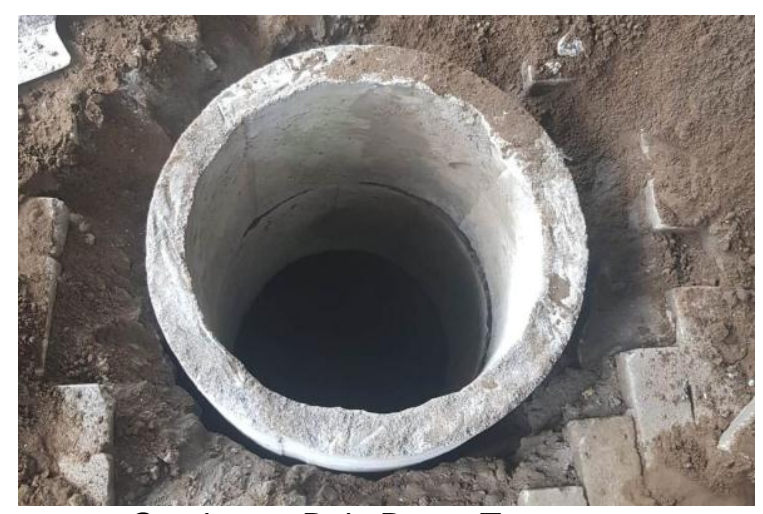

Gambar 5. Buis Beton Terpasang Sumber : (Nilawati, 2020)

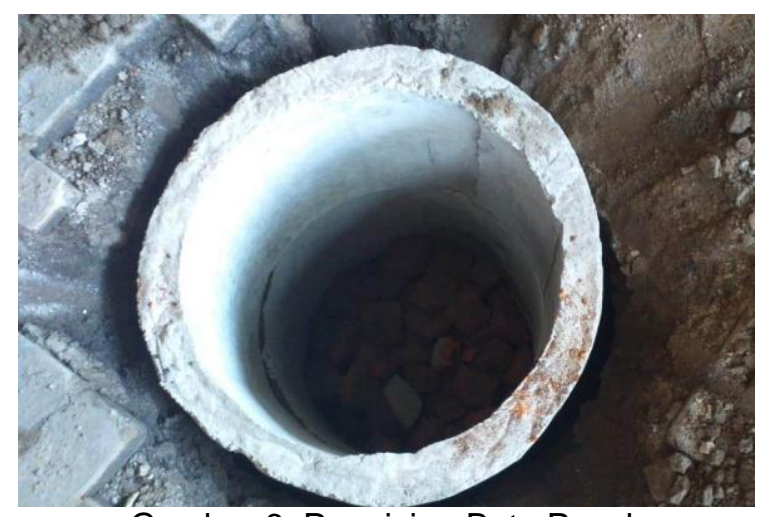

Gambar 6. Pengisian Batu Pecah

Sumber : (Nilawati, 2020)

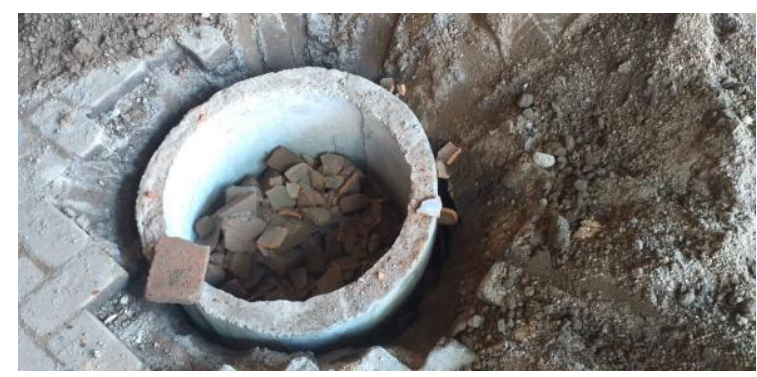

Gambar 7. Pengisian Puing Bata dan Genteng Sumber : (Nilawati, 2020)

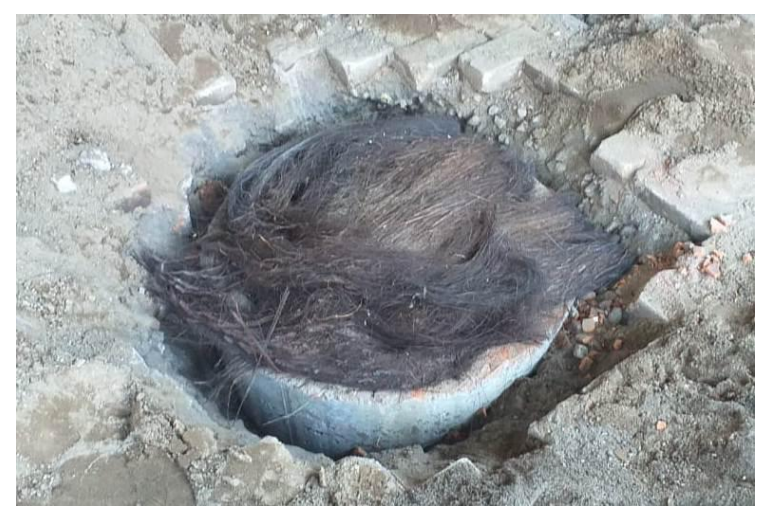

Gambar 8. Pengisian ljuk

Sumber : (Nilawati, 2020)

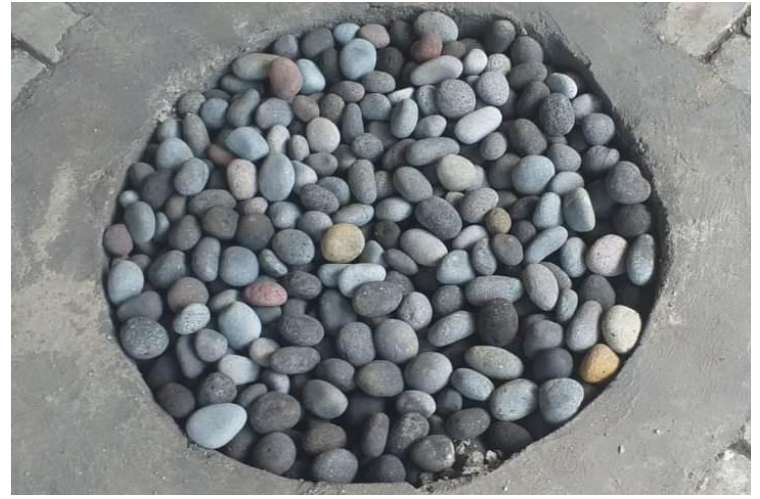

Gambar 9. Pengisian Batu Koral Sumber : (Nilawati, 2020)

\section{Kesimpulan dan Saran}

- Dari pembahasan penerapan sumur resapan untuk pengendalian air hujan pada area rumah tinggal dapat disimpulkan bahwa :

- Sumur resapan adalah salah satu usaha pengelolaan air sederhana yang dapat dilakukan oleh masyarakat pada area rumah tinggal. Prinsip dari sumur resapan ini adalah untuk mengisi air tanah kembali sehingga cadangan air tanah terjaga.

- Sumur resapan yang dibuat dengan kedalaman $1 \mathrm{~m}$ karena pada area titik sumur resapan sudah mencapai tanah berpasir. Air hujan yang masuk melalui sumur resapan melewati lapisan batu koral dan ijuk sebagai filter agar kotoran / sampah tidak masuk ke dalam sumur. Kemudian air akan melewati lapisan puing bata dan genteng, selanjutnya melewati lapisan batu pecah dan pada akhirnya mencapai lapisan tanah atau pasir dan langsung terserap sebagai air tanah.

- Luas area rumah tinggal pada penelitian ini adalah $500 \mathrm{~m}^{2}$, jumlah area sumur resapan adalah $4 \%$ dari area kedap air, yaitu $4 \% \times$ $200 \mathrm{~m}^{2}=8 \mathrm{~m}^{2}$, desain sumur resapan memiliki volume $0,78 \mathrm{~m}^{3}$. Total sumur resapan yang dibuat adalah $8 \mathrm{~m}^{2}: 0,78 \mathrm{~m}^{3}=$ 10 buah sumur resapan.

Hal-hal yang dapat disarankan adalah :

1. Pada area pembuatan sumur resapan dengan lokasi di bawah talang air, sebaiknya dibuatkan saluran pipa masuk dari talang air menuju sumur resapan supaya air hujan dapat langsung mengalir ke dalam sumur respaan. 
2. Tutup sumur resapan dapat dibuat dari plat beton bertulang tebal $10 \mathrm{~cm}$, campuran 1 semen, 2 pasir, 3 kerikil. Lubang sumur resapan harus ditutup untuk menjaga keamanan dan keselamatan

\section{Daftar Pustaka}

Badan Standardisasi Nasional. (2002). SNI No. 03-2453-2002.Tata Cara Perencanaan Sumur Resapan Air Hujan Untuk Lahan Pekarangan.

Corry Yohana, Dientje Griandini, \& Said Muzambeq. (2017). Penerapan Pembuatan Teknik Lubang Biopori Resapan Sebagai Upaya Pengendali Banjir. Pemberdayaan Masyarakat Madani (JPMM), 1, 296-308. https://doi.org/https://doi.org/10.21009/JP MM.001.1

Duppa, H. (2017). SUMUR RESAPAN UNTUK MENGURANGI GENANGAN AIR DAN BANJIR. In Jurnal Scientific Pinisi. https://doi.org/https://doi.org/10.26858/ijfs .v3i1.4380
Harris, S. (2015). Pemanfaatan Bak Resapan Dan Biopori Sistem Guna. Faktor Exacta, 8. https://journal.Ippmunindra.ac.id/index.ph p/Faktor_Exacta/article/view/320

Muliawati, D. N., \& Mardyanto, M. A. (2015). Perencanaan Penerapan Sistem Drainase Berwawasan Lingkungan (EkoDrainase) Menggunakan Sumur Resapan Di Kawasan Rungkut. Jurnal Teknik ITS, 4.

Peraturan Menteri Negara Lingkungan Hidup. (2010). Kriteria dan Sertifikasi Bangunan Ramah Lingkungan.

Simbolon, H., \& Nasution, I. N. (2017). DESAIN RUMAH TINGGAL YANG RAMAH LINGKUNGAN UNTUK IKLIM TROPIS. Educational Building. https://doi.org/10.24114/eb.v3i1.7443 